\title{
Determinan Gizi Lebih pada Remaja di SMP YPI Bintaro Jakarta
}

\author{
Tika Destiani ${ }^{1}$, Sintha Fransiske Simanungkalit ${ }^{2}$, A'immatul Fauziyah $^{3}$
}

Program Studi S1 IImu Gizi, Fakultas IImu Kesehatan, Universitas Pembangunan Nasional "Veteran" Jakarta, Jalan Raya Limo Depok 16515, Indonesia

Email : sintha_fs@yahoo.com

\begin{abstract}
Abstrak
Masa remaja yang memasuki masa kehidupan anak dan dewasa, berawal dari usia 9 - 10 tahun dan berakhir di usia I 8 tahun. Masa remaja termasuk golongan yang rentan dalam artian fisik, psikis, sosial, dan gizi. Tujuan dilakukannya penelitian ini adalah untuk mengetahui determinan yang berhubungan dengan status gizi pada remaja di SMP YPI Bintaro Jakarta. Penelitian ini menggunakan desain cross sectional. Sampel penelitian ini menggunakan siswa-siswi SMP YPI Bintaro yang memenuhi kriteria. Untuk mendapatkan data gizi lebih dilakukan pengukuran antropometri tinggi badan dan berat badan, pengisian lembar FFQ untuk konsumsi sayur dan buah, juga lembar kuesioner untuk variabel pengetahuan, teman sebaya, aktivitas fisik. Analisis data univariabel menggunakan distribusi frekuensi, bivariabel menggunakan uji Chi Square. Hasil penelitian ini ditemukan prevalensi gizi lebih pada remaja pada populasi penelitian ini adalah $5 \%$ dan menunjukan terdapat ada hubungan pada konsumsi sayur $(p=0,046)$, konsumsi buah ( $P$ $=0,039)$, pengetahuan $(p=0,046)$ dan aktivitas fisik $(p=0,039)$. Sekolah hendaknya bekerjasama dengan institusi kesehatan memberikan edukasi tentang gizi seimbang dan kesehatan terutama tentang gizi lebih.
\end{abstract}

Kata kunci : Remaja, Gizi lebih, Pengetahuan

\begin{abstract}
Adolescence who entered the lives of children and adults, starting from the age of $9-10$ years and ended at the age of 18 years. Adolescence included vulnerable groups in terms of physical, psychological, social, and nutrition. The purpose of this research is to know the determinant associated with nutritional state in adolescents in SMP YPI Bintaro Jakarta. This study used cross sectional design. The sample of this study used the students of SMP YPI Bintaro who fill the criteria. To obtain data over nutrition, anthropometry measurement of height and weight, FFQ sheet for vegetable and fruit consumption, also questionnaire for knowledge, peers, physical activity. Univariable data analysis used frequency distribution, bivariable used Chi Square Test. The result of this study found that the prevalence of over nutrition adolescents in this study population is $5 \%$ and shows consumption $(p=0.039)$, knowledge $(p=0.046)$ and physical activity $(p=0.039)$. Schools should cooperate with health institutions to educate on balanced nutrition and health, especially about over nutrition.
\end{abstract}

Keywords : Adolescents, Over nutrition, knowledge 


\section{Pendahuluan}

Remaja adalah masa perpindahan dari anak menuju dewasa. Remaja dapat dikategorikan rentan terkena masalah gizi. Masalah gizi pada remaja saat ini muncul karena perilaku gizi yang salah seperti ketidakseimbangan antara energi yang masuk dengan energi yang keluar sehingga menimbulkan gizi lebih. ${ }^{1}$ Konsumsi zat gizi yang tidak optimal berkaitan dengan kesehatan yang tidak baik, dapat meningkatkan faktor risiko yang berkaitan dengan penyakit tidak menular (PTM), seperti penyakit kardiovaskuler (hipertensi, penyakit jantung dan pembuluh darah, stroke), diabetes serta kanker yang merupakan penyebab utama kematian di Indonesia. $^{2}$

Data obesitas di Indonesia belum bisa menggambarkan data obesitas diseluruh penduduk. Menurut Kementerian Kesehatan RI dalam Riset Kesehatan Dasar, ${ }^{3}$ prevalensi gizi lebih pada remaja di Jakarta yaitu 4,2\% dan pada Riset Kesehatan Dasar (2013) ${ }^{4}$ prevalensi gemuk pada remaja 13 - 15 tahun di Indonesia yaitu $10,8 \%$, terdiri dari $8,3 \%$ gemuk (overweight) dan 2,5\% sangat gemuk (obesitas). Di Indonesia anak usia sekolah yang menderita kegemukan cenderung meningkat, yaitu sebesar $18,8 \%$ pada tahun 2013 meningkat dua kali lipat dibandingkan tahun 2010 yaitu 9,2\%..$^{5} \mathrm{Di}$ wilayah DKI Jakarta, prevalensi obesitas meningkat dengan bertambahnya usia. Pada umur 6 - 12 tahun ditemukan obesitas $4 \%$, pada remaja 12 - 16 tahun ditemukan $6,2 \%$ dan umur 17 - 18 tahun $11,4 \%$. Kasus obesitas pada remaja lebih banyak ditemukan pada perempuan, yaitu 10,2\% dibandingkan dengan laki-laki yang hanya $3,1 \%{ }^{6}$

Menurut World Health Organization (WHO) secara umum menganjurkan konsumsi sayur dan buah untuk hidup sehat sejumlah 400 gr per orang per hari, yang terdiri dari 250 gr sayur dan $150 \mathrm{gr}$ buah. Bagi orang Indonesia dianjurkan konsumsi sayur dan buah 300 - 400 gr per orang per hari bagi anak balita dan anak usia sekolah, dan 400 - 600 gr per orang per hari bagi remaja dan orang dewasa. Sekitar dua pertiga dari jumlah konsumsi sayur dan buah tersebut adalah porsi sayur. Menurut Mak, Prynne, Cole, dkk. kekurangan konsumsi sayur dan buah pada anak dapat menimbulkan berbagai penyakit kemudian hari. Rendahnya konsumsi sayur dan buah ini berkaitan dengan meningkatnya risiko terjadinya penyakit-penyakit kronik seperti penyakit jantung dan diabetes. ${ }^{7}$

Menurut penelitian Hendrayati, dkk, peningkatan pengetahuan, sikap dan keterampilan saling berinteraksi membentuk pola perilaku yang khas. ${ }^{8}$ Pengetahuan gizi pada remaja sangat penting karena setiap orang akan cukup gizi jika makanan yang dimakannya mampu menyediakan zat gizi yang diperlukan untuk pertumbuhan yang optimal, karena pengetahuan gizi memberikan informasi yang berhubungan dengan gizi, makanan dan hubungannya dengan kesehatan.

Menurut penelitian Ningsih, dkk, mengatakan bahwa pengaruh teman sebaya sangat berperan. ${ }^{9}$ Anak kelompok sebaya merumuskan dan memperbaiki konsep dirinya untuk dinilai oleh orang lain yang sejajar dengan dirinya. Remaja putri memiliki perhatian yang besar pada penampilan, salah satunya adalah pada bentuk tubuh. Mereka sering merasa kegemukan, sehingga berusaha untuk membatasi konsumsi makanan secara berlebihan.

Gizi lebih terjadi karena ketidakseimbangan antara pemasukan energi dan pengeluaran energi. Remaja banyak yang mudah mengalami gizi lebih dikarenakan kurangnya aktivitas fisik. ${ }^{10}$

Hasil pengamatan yang peneliti lakukan ditemukan 4 siswa dengan status gizi lebih dari 10 siswa di SMP YPI Bintaro. Berdasarkan latar belakang diatas, penelitian ini bertujuan untuk mengetahui hubungan konsumsi sayur, konsumsi buah, pengetahuan gizi, pengaruh teman sebaya, 
aktivitas fisik dengan gizi lebih pada remaja di SMP YPI Bintaro.

\section{Metode Penelitian}

Penelitian ini menggunakan metode kuantitatif dengan desain penelitian deskriptif korelasi dengan pendekatan cross sectional. Penelitian ini dilaksanakan pada bulan April 2018 di SMP YPI Bintaro Jakarta. Populasi adalah Siswa SMP YPI Bintaro Jakarta. Sebanyak 75 siswa terpilih sebagai sampel penelitian. Pemilihan sampel dilakukan acak sistematis (Sistematic Random Sampling).

Data primer untuk variabel independent dan variabel dependent dikumpulkan dalam waktu yang bersamaan. Variabel dependent yang diteliti adalah gizi lebih pada remaja, sedangkan variabel independent meliputi konsumsi sayur, konsumsi buah, pengetahuan gizi, pengaruh teman sebaya, dan aktivitas fisik. Pengumpulan data dilakukan dengan membagikan kuesioner kepada siswa, kemudian diberikan pengarahan mengenai cara pengisian kuesioner. Dan dilanjutkan dengan pengukuran antropometri (berat badan dan tinggi badan). Lalu responden akan diwawancarai mengenai konsumsi sayur dan buah juga mengisi lembar kuesioner tentang pengetahuan, pengaruh teman sebaya, dan aktivitas fisik.

\section{Hasil}

\section{Analisis Univariat}

Berdasarkan hasil penelitian ini dari 72 responden diketahui bahwa persentase tertinggi yaitu pada gizi lebih sebanyak 50 orang $(69,4 \%)$ dan persentase terendah yaitu pada gizi tidak lebih sebanyak 22 orang $(30,6 \%)$. Ini membuktikan bahwa lebih banyak anak remaja SMP yang mengalami gizi lebih dibandingkan gizi tidak lebih.

Tabel 1. Analisis Univariat

\begin{tabular}{llcc}
\hline \multicolumn{1}{c}{ Variabel } & \multicolumn{1}{c}{ Kategori } & n & \% \\
\hline Status Gizi & Gizi Lebih & 50 & 69,4 \\
& Gizi Tidak Lebih & 22 & 30,6 \\
Konsumsi & Kurang & 44 & 61,1 \\
Sayur & Baik & 28 & 38,9 \\
Konsumsi & Kurang & 44 & 61,1 \\
Buah & Baik & 28 & 38,9 \\
Pengetahuan & Kurang & 44 & 61,1 \\
Gizi & Baik & 28 & 38,9 \\
Aktivitas & Ringan & 50 & 69,4 \\
Fisik & Sedang & 22 & 30,6 \\
\hline
\end{tabular}

Berdasarkan hasil penelitian ini 72 responden diketahui bahwa persentase konsumsi sayur tertinggi yaitu pada konsumsi sayur dengan asupan kurang sebanyak 44 orang $(61,1 \%)$ dan persentase konsumsi sayur terendah yaitu pada konsumsi sayur dengan asupan baik sebanyak 28 orang $(38,9 \%)$. Ini membuktikan bahwa lebih banyak anak remaja SMP yang konsumsi sayurnya masih kurang.

Berdasarkan hasil penelitian ini 72 responden diketahui bahwa persentase konsumsi buah tertinggi yaitu pada konsumsi buah dengan asupan kurang sebanyak 44 orang $(61,1 \%)$ dan persentase konsumsi buah terendah yaitu pada konsumsi buah dengan asupan baik sebanyak 28 orang $(38,9 \%)$.

Tabel 2. Analisis Bivariat

\begin{tabular}{|c|c|c|c|c|c|c|}
\hline \multirow{3}{*}{ Variabel } & \multirow{3}{*}{ Konsumsi Sayur } & \multicolumn{4}{|c|}{ Gizi Lebih } & \multirow{3}{*}{ P value } \\
\hline & & \multicolumn{2}{|c|}{ Gizi Lebih } & \multicolumn{2}{|c|}{ Gizi Tidak Lebih } & \\
\hline & & $\mathbf{n}$ & $\%$ & $\mathbf{n}$ & $\%$ & \\
\hline \multirow[t]{2}{*}{ Konsumsi Sayur } & Asupan Kurang & 26 & 59,1 & 18 & 40,9 & \multirow{2}{*}{0,020} \\
\hline & Asupan Baik & 24 & 85,7 & 4 & 14,3 & \\
\hline \multirow[t]{2}{*}{ Konsumsi Buah } & Kurang & 36 & 81,8 & 8 & 18,2 & \multirow{2}{*}{0,009} \\
\hline & Baik & 14 & 50 & 14 & 50 & \\
\hline \multirow{2}{*}{ Pengetahuan Gizi } & Kurang & 26 & 59,1 & 18 & 40,9 & \multirow{2}{*}{0,033} \\
\hline & Baik & 24 & 85,7 & 4 & 14,3 & \\
\hline \multirow[t]{2}{*}{ Aktivitas Fisik } & Ringan & 39 & 78 & 11 & 22 & \multirow{2}{*}{0,036} \\
\hline & Sedang & 11 & 50 & 11 & 50 & \\
\hline
\end{tabular}


Ini membuktikan bahwa lebih banyak anak remaja SMP yang konsumsi buahnya masih kurang.

Berdasarkan hasil penelitian ini 72 responden diketahui bahwa persentase pengetahuan gizi tertinggi yaitu pada pengetahuan gizi yang kurang sebanyak 44 orang $(61,1 \%)$ dan persentase pengetahuan gizi terendah yaitu pada pengetahuan gizi yang baik sebanyak 28 orang (38,9\%). Ini membuktikan bahwa lebih banyak anak remaja SMP yang pengetahuan tentang gizinya masih kurang.

Berdasarkan hasil penelitian ini 72 responden diketahui bahwa persentase aktivitas fisik tertinggi yaitu pada aktivitas fisik yang aktivitasnya ringan sebanyak 50 orang $(69,4 \%)$ dan persentase aktivitas fisik terendah yaitu pada aktivitas fisik yang aktivitasnya sedang sebanyak 22 orang $(30,6 \%)$. Ini membuktikan bahwa lebih banyak anak remaja SMP yang aktivitasnya kurang dengan frekuensi tertinggi diaktivitas ringan.

\section{Pembahasan}

Berdasarkan hasil uji statistik dengan $\alpha=5 \%$, diperoleh $\mathrm{p}$ value $=0,020$ sehingga dapat disimpulkan bahwa terdapat hubungan yang signifikan antara konsumsi sayur dengan gizi lebih pada remaja SMP.

Penelitian ini sejalan dengan
beberapa penelitian lainnya yang
menyatakan konsumsi sayur dengan gizi lebih pada remaja. Sayur dan buah merupakan sumber serat yang penting bagi anak dalam masa pertumbuhan, khususnya berhubungan dengan obesitas. Anak overweight dan obesitas membutuhkan makanan tinggi serat seperti sayur dan buah. ${ }^{11}$

Berdasarkan hasil uji statistik dengan $\alpha=5 \%$, diperoleh $\mathrm{p}$ value $=0,009$ sehingga dapat disimpulkan bahwa terdapat hubungan yang signifikan antara konsumsi buah dengan gizi lebih pada remaja SMP.

Penelitian ini sejalan dengan beberapa penelitian lainnya yang menyatakan ada hubungan antara konsumsi buah dengan gizi lebih pada remaja. Penelitian yang dilakukan oleh Nany, Rosihan, dan Hesti pada Siswa SMP di Perkotaan dan Pedesaan Kotamadya Banjarbaru pada Tahun 2014, menunjukkan terdapat hubungan signifikan antara konsumsi buah dengan status gizi yang dapat dilihat dari hasil analisis uji statistik penelitian dengan $\mathrm{p}$ value 0,000 (p $<0,05)$. Masih rendahnya konsumsi buah di Indonesia terkait dengan beberapa faktor, disamping pendapatan, konsumsi buah tersebut juga terkait dengan masalah masih rendahnya kesadaran mengkonsumsi buah (sebagai sumber vitamin dan mineral), rendahnya ketersediaan buah, dan kurangnya keterjangkauan konsumsi produksi buah oleh rumah tangga. ${ }^{12}$

Berdasarkan hasil uji statistik dengan $\alpha=5 \%$, diperoleh $\mathrm{p}$ value $=0,033$ sehingga dapat disimpulkan bahwa terdapat hubungan yang signifikan antara pengetahuan gizi dengan gizi lebih pada remaja SMP.

Pengetahuan gizi merupakan pengetahuan tentang makanan dan zat gizi, sumber-sumber zat gizi pada makanan, makanan yang aman dikonsumsi sehingga tidak menimbulkan penyakit dan cara mengolah makanan yang baik agar zat gizi dalam makanan tidak hilang serta bagaimana hidup sehat. ${ }^{13}$ Dengan pengetahuan gizi yang baik, seseorang akan mengetahui banyak tentang yang berhubungan dengan makanan yang mencakup bahan makanan, fungsi bagi kebutuhan tubuh, sumber bahan makanan serta akibat kelebihan dan kekurangan bahan makanan. ${ }^{14}$

Berdasarkan hasil uji statistik dengan $\alpha=5 \%$, diperoleh $\mathrm{p}$ value $=0,036$ sehingga dapat disimpulkan bahwa terdapat hubungan yang signifikan antara aktivitas fisik dengan gizi lebih pada remaja SMP.

Penelitian ini sejalan dengan beberapa penelitian lainnya yang menyatakan ada hubungan antara aktivitas fisik dengan gizi lebih pada remaja. 
Sebuah penelitian yang dilakukan di Serang menunjukkan terdapat hubungan signifikan antara aktivitas fisik dengan status gizi lebih yang dapat dilihat hasil uji statistik penelitian dengan $\mathrm{p}$ value $0,000 .{ }^{15}$ Aktivitas fisik berhubungan dengan kejadian obesitas sentral sebesar 9,75 kali. Terjadinya obesitas dikarenakan rendahnya aktivitas fisik yang dilakukan siswa sehingga asupan energi yang masuk ke dalam tubuh hanya sedikit terpakai untuk beraktivitas dan sebagian besar tersimpan sebagai lemak tubuh, dengan kata lain kelompok obesitas hanya menggunakan sedikit energi. ${ }^{16}$

\section{Kesimpulan}

Dari hasil penelitian dapat disimpulkan bahwa gizi lebih masih banyak dialami oleh remaja di SMP YPI Bintaro. Gizi lebih berdasarkan hasil penelitian ini berhubungan dengan faktor konsumsi sayur, konsumsi buah, pengetahuan tentang gizi, dan faktor aktivitas fisik remaja di SMP YPI Bintaro.

\section{Saran}

Bagi remaja disarankan meningkatkan pengetahuan tentang gizi dan diterapkan sebaik mungkin di dalam kehidupan sehari-hari, juga disarankan untuk menjaga asupan makan terutama mengkonsumsi sayur dan buah serta melakukan aktivitas fisik untuk menghindari resiko terjadinya gizi lebih. Sekolah hendaknya bekerjasama dengan institusi kesehatan memberikan edukasi tentang gizi seimbang dan kesehatan terutama tentang gizi lebih

\section{Daftar Pustaka}

1. Ambarita MM. Faktor Risiko Penyebab Kejadian Gizi Lebih pada Mahasiswa Akademi Kebidanan Agatha Yayasan Vala Agatha Pematangsiantar Tahun 2014. Program Sarjana Fakultas Kesehatan Masyarakat. Universitas Sumatera utara: Medan; 2014.

2. Sugihantono A. Pedoman Umum Gizi Seimbang. Jakarta: Rineka Cipta; 2014.

3. RISKESDAS. Laporan Riset Kesehatan Dasar. Badan Penelitian dan Pengembangan Kesehatan Kementrian RI; 2010.
4. RISKESDAS. Laporan Riset Kesehatan Dasar. Badan Penelitian dan Pengembangan Kesehatan Kementrian RI; 2013.

5. Hermina dan Prihatin. Gambaran Konsumsi Sayur dan Buah Penduduk Indonesia dalam Konteks Gizi Seimbang: Analisis Lanjut Survei Konsumsi Makanan Individu (SKMI) 2014. Jakarta: Pusat Penelitian dan Pengembangan Upaya Kesehatan Masyarakat; 2014

6. Sjarif DR. Childhood Obesitaty: Evaluation and Management. Dalam : Soebagiyo (Eds). Naskah Lengkap National Obesitaty Symposium II, Surabaya. Sjarif. D.R. 2003. Childhood Obesitaty: Evaluation and Management. Dalam : Soebagiyo (Eds). Naskah Lengkap National Obesitaty Symposium II, Surabaya; 2003.

7. Mak, Tzh Ning, Prynne, Cole, dkk. Assessing Eating Context and Fruit and Vegetable Consumption in Children: New Methods Using Food Diaries in the UK National Diet and Nutrition Survey Rolling Programme. International Journal of Behavioural Nutrition and Physical Activity; 2012.

8. Hendrayati dkk. Pengetahuan Gizi, Pola Makan, dan Status Gizi Siswa SMP Negeri 4 Tompobulu Kabupaten Bantaeng. Jurnal: Media gizi pangan, Vol. IX, Edisi 1. Jurusan Gizi, Politeknik Kesehatan: Makassar; 2010.

9. Ningsih R, dkk. Hubungan Teman Sebaya, Konsep Diri dan Status Gizi Remaja Putri. Jurnal: Jurusan Keperawatan Poltekkes Kemenkes Jakarta III, Jakarta; 2014.

10. Rachmad, dkk. Obesitas Permasalahan dan Terapi Praktis. Jakarta: Sagung Seto; 2009.

11. Field AE, Gilman MW, Rosner B, Rockett HR, Colditz GA. Association between Fruit and Vegetable Intake and Change in Body Mass Index among a Large Sample of Children and Adolescents in the United States. Int. J. Relat. Metab. Disord; 2003.

12. Wulansari ND. Konsumsi Serta Preferensi Buah dan Sayur pada Remaja SMA Dengan Status Sosial Ekonomi yang Berbeda di Bogor. Departemen Gizi Masyarakat, Fakultas Ekologi Masyarakat, IPB. Bogor; 2009.

13. Notoatmodjo S. Pendidikan dan Perilaku Kesehatan. Jakarta: PT Rineka Cipta; 2003.

14. Baliwati, dkk. Pengantar Pangan dan Gizi. Jakarta: Penebar Swadaya; 2004.

15. Suharsa dan Sahnaz. Status Gizi Lebih dan Faktor-Faktor Lain yang Berhubungan pada Siswa Sekolah Dasar Islam Tirtayasa Kelas IV dan V di Kota Serang Tahun 2014. Jurnal Lingkar Widyaiswara. Fakultas Ilmu Kesehatan, Universitas Mathlaul Anwar, Banten; 2016.

16. Musralianti F, dkk. Hubungan Antara Aktivitas Fisik dan Pola Makan dengan Kejadian Obesitas pada Siswa Di SMP Kristen Eben Haezar 1 Manado. PHARMACON J Ilm Farm UNSRAT; 2016. 